\title{
The Effects of Natural Antioxidant on the Efficiency of Lubricant Oil
}

\author{
T. TAlib Issa Al-Omran* \\ University of Baghdad, College of Science, Physics Department, Jadiriya, Baghdad, Iraq
}

\begin{abstract}
Specimens from industrial lubricant oils of two types were investigated. The first type was used for internal combustion engines and the second was used for electrical distribution transformers. The flash point, pour point, viscosity, and brake down voltage tests are done under $100{ }^{\circ} \mathrm{C}$ for $48 \mathrm{~h}$ and after this there is added the natural antioxidant curcumin in a powder form having $75 \mu \mathrm{m}$ grain size. Curcumin of different weight percentage ranging from 1 to 5 was well mixed with the lubricant oil. The well dissolved specimens were investigated according to the ASTM methods. The significant improvement in all the properties was achieved after adding the natural antioxidant (curcumin) and reached its maximum value at the combination oil-curcumin $3 \mathrm{wt} \%$. The well dissolved mixture indicates the reason of the improvement in the two types of oil efficiency and can stand with over temperature.
\end{abstract}

DOI: 10.12693/APhysPolA.134.426

PACS/topics: efficiency, lubricant, oil, antioxidant

\section{Introduction}

World demand for lubricants is forecast to increase 2.4 percent per year to 43.6 million metric tons in 2017 . Driven by strong growth in vehicle ownership and ongoing industrialization in the developing countries, lubricants used in the manufacturing market will expand more rapidly than motor vehicles, driven by rising manufacturing output in developing countries. Asia, Eastern Europe, South America, and Africa/Mideast will benefit from the continued shift of global manufacturing activity to these regions. This trend will drive healthy growth in manufacturing lubricant demand; however, as is the case for motor vehicle lubricants, improving lubricant efficiency will restrain even stronger gains. Other markets, including agriculture, construction, and nonmotor vehicle transportation, will in aggregate outpace motor vehicle and manufacturing markets through 2017. Healthy economic growth, investment in infrastructure and other construction, and the increasing mechanization in developing countries will result in strong performance in these markets. It is generally known that preventing the oxidation degradation of oil is necessary to develop long life performance. Lubricant oils were used in machines, engines, rolling bearings, pistons linear system, turbo charger, etc., and to improve the efficiency of machines for an extra reliability of the rotary components when used for an extra time at a higher operating temperature, the oil will be deteriorated by oxidation, there for antioxidant will be needed to help inhibit deteriorated in its lubricating performance. Various antioxidants have been commercially used for this purpose. In antioxidants boast greater benefits when added into grease, since they themselves make stable radicals that help terminate chain atoms reactions while they donate

*corresponding author; e-mail: alazbrh@yahoo.com hydrogen atoms. Most phenolic antioxidants used in lubricating grease are phenolic derivatives having a treating butyl group [1, 2]. The huge amounts of used oil, lead to study how to improve and develop its performance.

Improve the industrial lubricant oil specifications of great practical significance and economic feasibility of large-considered and that the huge amounts of used oil and can be used through the addition of certain material to improve some of its properties, according to the nature of its work and its kind. It is well known that the presentation of oxidation and decomposition of the oil is very important. The mechanical effect of oxidation stress on the oil in which increase the process of decomposition to the roots (radicals), due to increased temperature and radicals with the oxygen molecule composed with roots. The formed peroxide will interact with two of oil molecules composed extra roots [3]. To minimize and reduce these mechanical effects by effective antioxidants, could be classified as two types. The first is primary antioxidant to stop the series decomposition process and the second is secondary antioxidant that prevents the decomposition of forming the peroxide. Some researchers study the weight decrease with lubricating oil having been allowed to stand at higher temperature [3], others study the magnitude of oxidative deterioration inhibition effects of natural antioxidants [4]. In the present study we used a natural additive antioxidant, which is curcumin, 1.7-bis (4-hydrogen-3-methoxy-phenyl 1-1,6heptadiene-3,5-dione). Curcumine is thermally stable up to $249^{\circ} \mathrm{C}$, having a unique shape of differential thermal analysis (DTA) [5]. It is turmeric yellow, is an orange crystalline compound which is insoluble in water, but soluble in some organic solvents [6]. It finds many applications in food and dye industries and agriculture. The annual word consumption of this natural dye, which is obtained from the plant Curcumin longas, is more than 300000 tons. We are focused on the improvement of the performance properties for tow types of lubricant oil after adding the curcumin as natural antioxidant material. 
The huge amount for using the lubricant oils all over the world diverge our intrastate to reuse this oils again after improving its performance and it will be helped economically by first reduce engines maintains, second reduce emissions, third reduce impacts after treatment system coast and performance. More over supporting environmental idea.

\section{Materials and equipments}

We have added the curcumin as powder of $75 \mu \mathrm{m}$ grain size into two types of lubricant oils and determined tests representative by the flash point, pure point, viscosity for the internal combustion oil and the same was done for the electrical transformer lubricant oil with break down voltage test. The 1, 2, 3, 4, $5 \mathrm{wt} \%$ of curcumin were added to each type and the specimens were then allowed to stand at $100{ }^{\circ} \mathrm{C}$ for 48 hours, there by the homogenizing mixtures were achieved without any participation for the antioxidant against the lubricant oils. The tests were done according to the ASTM methods. We used the Tanaka flash point control device, Japan, for testing the flashpoint under $100^{\circ} \mathrm{C}$. The pour point was tested by using the Petro test pour point taste device, Germany, under temperature up to $-51^{\circ} \mathrm{C}$, while the viscosity test was done by using the Brook field viscometer device, USA, under $100^{\circ} \mathrm{C}$. Finally the break down voltage measured by Megger device, UK, under $100^{\circ} \mathrm{C}$.

\section{Results and discussion}

The clear improvements were detected after adding the curcumin at all the tests, flush point, pour point, viscosity, and break down voltage. The results obtained showed that the enhancement was indicated at all the specimens of oil-1, 2, 3, 4, $5 \mathrm{wt} \%$ curcumin, respectively, and reached the maximum value at the combination oil-3 wt\% curcumin, while decrease in improved values was achieved at the combination oil-4, $5 \mathrm{wt} \%$ curcumin. In relation with the first type and from Fig. 1, the flash point was increased steadily reaching maximum value at $3 \mathrm{wt} \%$ curcumin, followed by decrease with stable values at $5 \mathrm{wt} \%$ curcumin. The same behavior was indicated for the pure point and the viscosity as shown in Fig. 2

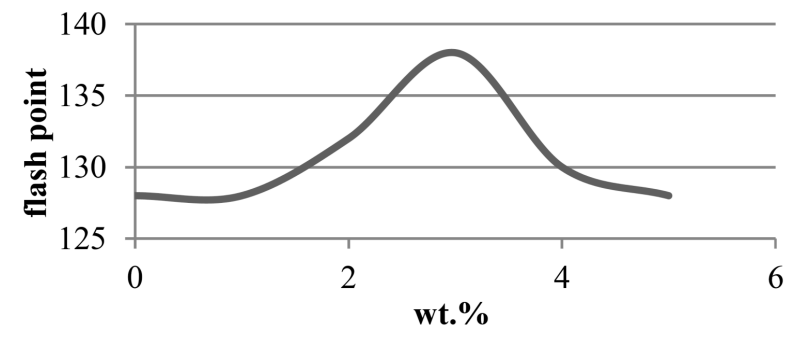

Fig. 1. The flash point test under $100^{\circ} \mathrm{C}$, for the internal combustion engine oil with respect to the wt\% curcumin.

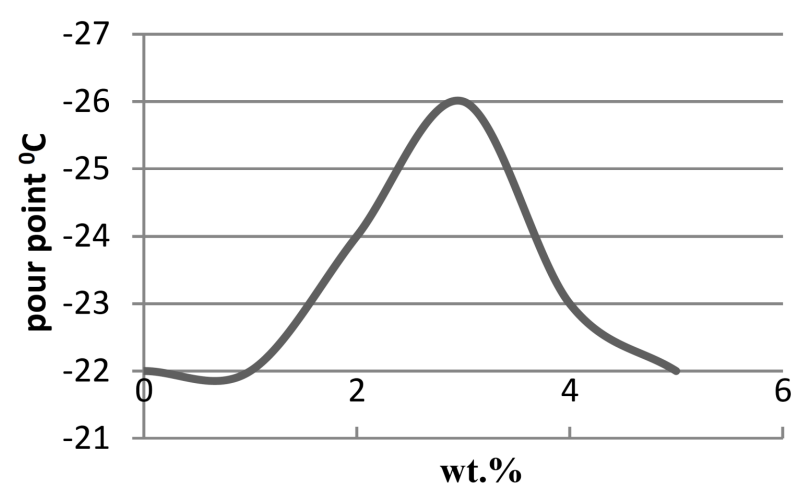

Fig. 2. The pour point test, for the internal combustion engine oil with respect to the wt\% curcumin.

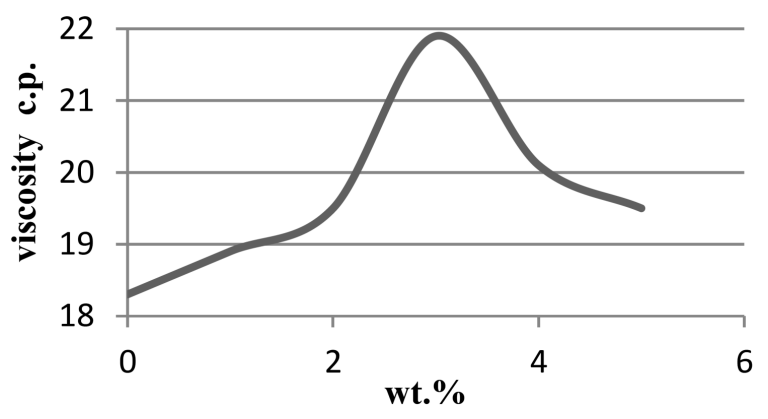

Fig. 3. The viscosity test under $100{ }^{\circ} \mathrm{C}$, for the internal combustion engine oil with respect to the wt\% curcumin.

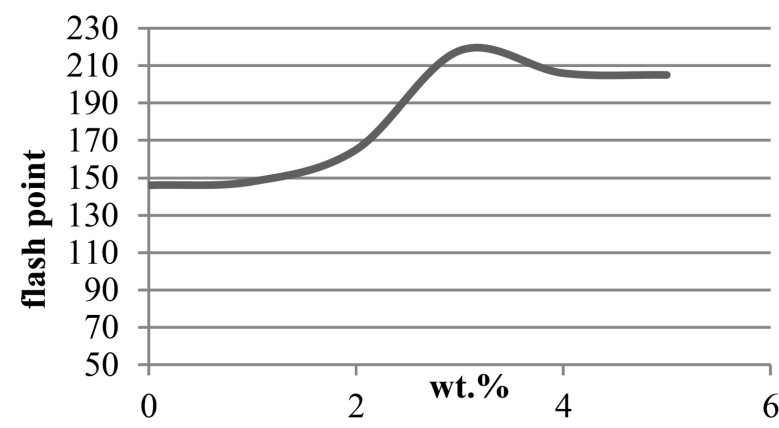

Fig. 4. The flash point test under $100{ }^{\circ} \mathrm{C}$, for the electrical transformers oil with respect to the wt\% curcumin.

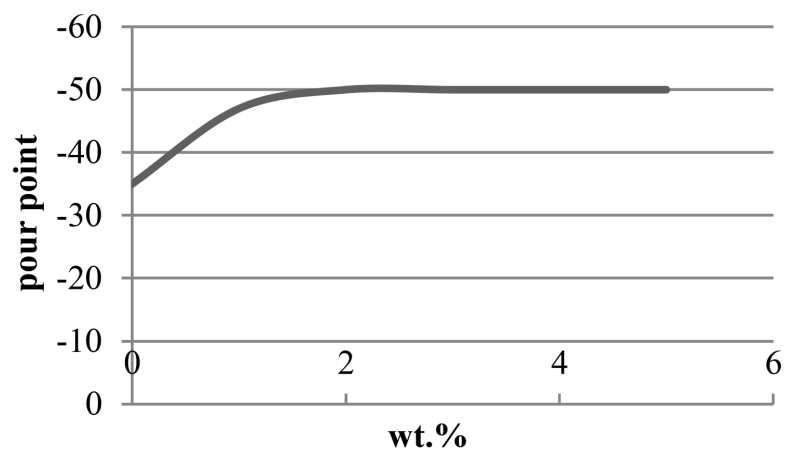

Fig. 5. The pour point test under $100^{\circ} \mathrm{C}$, for the electrical transformers oil with respect to the wt\% curcumin. 


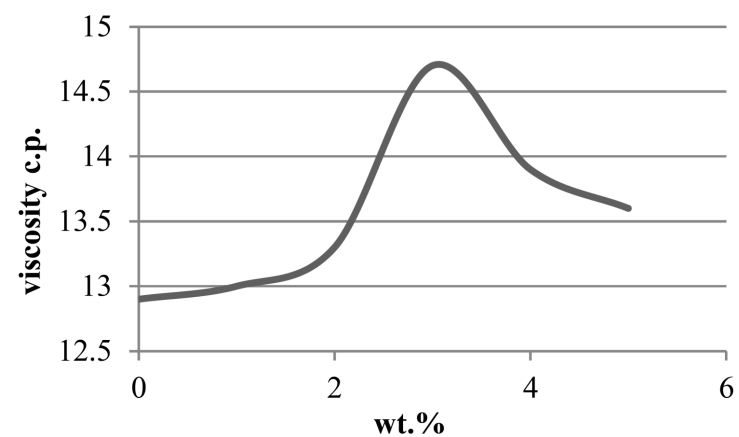

Fig. 6. The viscosity test under $100^{\circ} \mathrm{C}$, for the electrical transformers oil with respect to the wt\% curcumin.

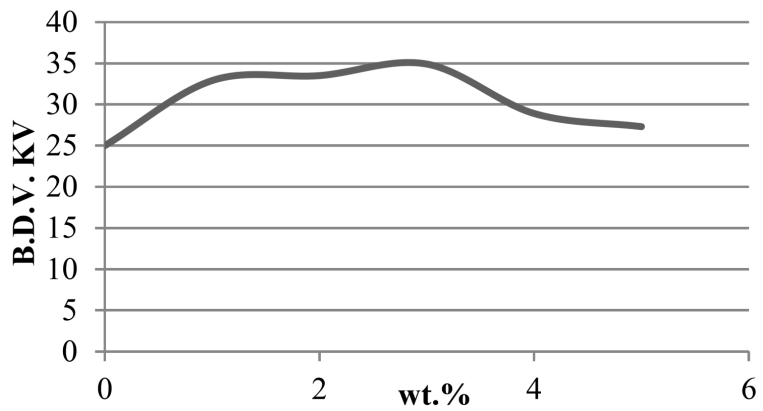

Fig. 7. The break down voltage test under $100^{\circ} \mathrm{C}$, for the electrical transformers oil with respect to the wt\% curcumin.

and Fig. 3, respectively. The second type tests representative by the flash point, pour point, viscosity, and breakdown voltage, reflects the same indication as in the first type. All results showed that the best was achieved at the combination lubricant oil-3 wt\% curcumin. As shown in Figs. 4-7, respectively, it was attempted to determine an optimal amount of as the nature additive tests which act to minimize and reduce the mechanical effects (oxidative deterioration) and to be able to withstand use for an extended period at higher temperature [6], specially at the weight percentage 3 , which is dissolved totally with the lubricant oil and leads to the significant improvement. The decrease in the improved values (still batter after adding curcumin), are most probably caused by a certain portion of the addition of curcumin remaining non solved in the lubricant oil.

\section{Conclusion}

The significant improvements were achieved for all the properties of the lubricant oil after adding the curcumin as a natural antioxidant representative by the flash point, pour point, viscosity and break down voltage. This improvement was signed as a remarkable one at the combination oil-3 wt\% curcumin.

\section{Acknowledgments}

We express our grateful to all who supported this work and provided his acknowledge and facilities, especially to the quality control lab staff in the State Commission of Research and Development, Ministry of Industry.

\section{References}

[1] S.A. Ghani, N.A. Muhamad, Z.A. Noorden, H. Zainuddin, A.A. Ahmad, IEEE Trans. Dielectr. Electric. Insulat. 24, 1674 (2017).

[2] L.A. Quinchia, M.A. Delgado, C. Valencia, J.M. Franco, C. Gallegos, J. Agricult. Food Chem. 59, 12917 (2011).

[3] R. Kreivaitis, M. Gumbyte, K. Kazancev, J. Padgurskas, V. Makarevičiéne, Industr. Crops Prod. 43, 511 (2013).

[4] M. Gonzalez, R. Gallego, M.A.R. Carrasco, J.A.G. Delgado, J.F. Arteaga, C. Valencia, J.M. Franco, Industr. Crops Prod. 87, 297 (2013).

[5] F. Jasim, T. Talib, J. Therm. Anal. 38, 2549 (1992).

[6] F. Jasim, F. Ali, J. Therm. Anal. 39, 156 (1989). 